\title{
A RELAÇÃO ENTRE NATIVO E ESTRANGEIRO NA IRLANDA DO TIGRE CELTA - ANÁLISE DO FILME ONCE, DE JOHN CARNEY, ATRAVÉS DA FILOSOFIA DIALÓGICA DE MARTIN BUBER
}

\author{
THE RELATIONSHIP BETWEEN NATIVE AND FOREIGNER IN \\ CELTIC TIGER IRELAND - AN ANALYSIS OF JOHN CARNEY'S \\ FILM ONCE THROUGH MARTIN BUBER'S DIALOGICAL \\ PHILOSOPHY
}

\author{
Sanio SANTOS DA SILVA ${ }^{1}$ \\ Noélia BORGES DE ARAÚJO²
}

\begin{abstract}
Resumo: Once (2007) é um musical irlandês escrito e dirigido por John Carney. Trata-se de uma história que expõe relações entre estrangeiros e locais na Irlanda do Tigre Celta - um período no qual o país passa por modificações econômicas e sociais. O filme é protagonizado por uma imigrante tcheca e um músico de rua irlandês. Eles se tornam amigos e decidem cooperar na gravação de canções. $\mathrm{O}$ interesse do presente trabalho está ligado à relação entre irlandês e estrangeiro representada no filme, considerando os aspectos protecionistas da irlandesidade e as mudanças sociais e ideológicas promovidas pelo Tigre Celta. Perscrutamos teorias relacionadas a nação, identidade e irlandesidade para compreender a função da identidade nacional em terras irlandesas antes e durante o Tigre Celta. A relação entre os dois indivíduos será interpretada a partir da obra $E u$ e $T u$, do filósofo Martin Buber (2006). O autor afirma que relações podem ser mediadas por ideias preconcebidas, ou imediatas e livres de obstáculos culturais. Assim, discutimos questões teóricas para compreender o caráter do elo entre o sujeito nativo e o estrangeiro na Irlanda do Tigre Celta. Observam-se percepções de um irlandês que hostiliza estrangeiros. Porém, considerando a singularidade da relação humana, é possível a existência de um contato que não seja completamente mediado por questões culturais e identitárias. Once expõe a possibilidade de romper com fortes ideologias de exaltação cultural dentro do contexto multicultural da globalização.
\end{abstract}

Palavras chaves: Once. Tigre Celta. Martin Buber. Relação. Irlandesidade.

Abstract: Once (2007) is an Irish musical written and directed by John Carney. It is a story that exposes relations between foreigners and locals in Celtic Tiger Ireland - a period in which the country goes through economic and social changes. The film is led by a Czech immigrant and an Irish busker. They become friends and decide to cooperate in recording songs. The interest of the present work regards the relation between the Irish and the foreign subjects represented in the film, considering the protectionist aspects of Irishness and the social and ideological changes promoted by the Celtic Tiger. We researched theories related to nation, identity and Irishness to understand the function of national identity in Irish lands before and during the Celtic Tiger. The relationship between the two individuals will be interpreted through the work Eu e Tu by the philosopher Martin Buber (2006). The author states that relations can be mediated by preconceived ideas, or can be immediate and free of cultural obstacles. Thus, we discuss theoretical questions to understand the character of the link between the native subject and the foreigner in Celtic Tiger Ireland. Perceptions of an Irishman who harasses foreigners are observed. However, considering the uniqueness of the human relationship, it is possible to have a contact that is not

\footnotetext{
${ }^{1}$ Graduado em Psicologia pela Universidade Salvador (UNIFACS). Mestrando no Programa de Pós-Graduação em Literatura e Cultura no Instituto de Letras da Universidade Federal da Bahia. E-mail: sanio.santos@gmail.com ${ }^{2}$ Professora e pesquisadora do Instituto de Letras da Universidade Federal da Bahia. Possui mestrado em Letras pela Universidade Federal de Santa Catarina e doutorado em Estudos Linguísticos e Literários em Inglês pela Universidade de São Paulo. E-mail: nollybor2003@yahoo.com.br
} 
completely mediated by cultural and identity issues. Once exposes the possibility of breaking with strong ideologies of cultural exaltation inside the multicultural context of globalization.

Keywords: Once. Celtic Tiger. Martin Buber. Relationship. Irishness.

\section{Introdução}

Once (2007) é um musical romântico irlandês que conta a história da relação entre um músico de rua local e uma imigrante tcheca. Eles se conhecem na Grafton Street, uma rua movimentada da cidade de Dublin. Ao perceberem que compartilham do mesmo interesse por música, decidem cooperar na gravação de algumas canções num estúdio. O filme foi escrito e dirigido pelo dublinense John Carney e financiado pelo Irish Film Board ${ }^{3}$. O orçamento total foi de $\$ 150,000$, mas o filme teve grande sucesso de bilheteria, arrecadando mais de $\$ 230,000,000$ e, em 2008, conquistou o Oscar de melhor canção original com "Falling Slowly"4. A história aborda questões contemporâneas da Irlanda, a exemplo das mudanças demográficas, econômicas e sociais impulsionadas pelo Tigre Celta. Nesse sentido, torna-se um objeto de estudo relevante para compreender o contexto cultural e as produções fílmicas e literárias da Irlanda contemporânea. Estudos ligados ao cinema e à literatura irlandesa ainda são raros no Brasil, sobretudo na região Nordeste. O presente trabalho oferece uma contribuição para a diversidade dos trabalhos acadêmicos locais e privilegia o diálogo cultural entre Brasil e Irlanda.

Para a compreensão de Once, faz-se necessário observar o desenvolvimento da identidade irlandesa através da história e, principalmente, o momento econômico da produção do filme. $\mathrm{O}$ termo Tigre Celta surge em 1994, a partir da comparação do desempenho econômico da Irlanda com o dos tigres asiáticos. Segundo Colin Coulter e Steve Coleman (2003), o período aquece a economia e atrai empresas para o país. Consequentemente, imigrantes, requerentes de asilo e refugiados começam a perceber oportunidades em terras irlandesas. Contudo, ainda segundo Coulter e Coleman (2003), o boom econômico não atingiu todas as esferas sociais, e estrangeiros podem não ter vivências tão lucrativas.

Nesse cenário, a Irlanda começa a receber um grande volume de estrangeiros, o que modifica seu contingente populacional. Em períodos anteriores, os irlandeses eram um grupo essencialmente homogêneo, sendo a maioria formada por cristãos católicos e brancos. Coulter

\footnotetext{
${ }^{3}$ O Irish Film Board, que hoje atua com o nome Screen Ireland, é uma instituição que objetiva financiar e promover a produção irlandesa para cinema e televisão. Disponível em: 〈https://www.screenireland.ie〉. Acesso em: 01 jun. 2018.

${ }^{4}$ Informações do site Consequence Of Sound. Disponível em: <https://consequenceofsound.net/2017/08/tenyears-of-once-an-oral-history-of-john-carneys-hit-musical> Acesso em: 03 jun. 2018.
} 
e Coleman (2003) reportam que os nativos se mostraram hostis a determinados grupos de estrangeiros. Mesmo na globalização, o irlandês parece ter uma atitude protecionista com seu território e sua identidade. Tal comportamento pode estar ligado a um histórico de invasões e conflitos, principalmente com a coroa britânica, o que levou o irlandês a desenvolver um forte nacionalismo cultural em nome da busca pela independência política. Once vem romper com tais ideologias nacionalistas - que beiram a xenofobia -, e posiciona o imigrante em uma relação horizontal com o nativo.

Pretende-se aqui analisar a relação entre o imigrante e o irlandês representada em Once através da filosofia de Martin Buber (2006). Trabalhamos com a obra Eu e Tu, onde o autor propõe que o contato do homem com o mundo é mediado por duas palavras-princípio - Eu-Tu ou Eu-Isso. Relações mediadas pelo Eu-Tu são desvinculadas de experiências anteriores. $\mathrm{O}$ homem acessa o outro em sua totalidade sem obstáculos culturais, religiosos, econômicos ou científicos. Na dimensão do Eu-Isso, o sujeito medeia suas relações através de memórias e ideais preconcebidos, o que impossibilita surpresas e descobertas. Assim, propomos uma análise, através da representação fílmica, de como o irlandês articula sua relação com o indivíduo estrangeiro. Está o nativo aberto à multiculturalidade, ou ainda recusa a influência estrangeira e preza pela exaltação de sua identidade nacional? Tais questionamentos serão respondidos nas próximas seções do trabalho.

\section{A nação}

A nação pode ser considerada como uma forma de agrupamento humano, uma maneira moderna desenvolvida pela sociedade para atribuir classificações às comunidades. Para Eric Hobsbawm (1990), o conceito de nação pertence a um período histórico recente, uma ordenação variável que não deve ser compreendida como o ponto de partida para classificação do homem. $\mathrm{O}$ autor ainda afirma que nações podem tomar ou excluir culturas preexistentes em nome do mito de que a nação é um modo natural de existência humana. Trata-se de uma compreensão da nacionalidade como uma característica inata, uma ideia, por vezes ligada ao divino, de que os homens devem ser distinguidos a partir de suas nações, tal como são categorizados por gênero ou cor de pele.

Dentro de tal arranjo, existe um laço invisível que une e permite a manutenção da ideologia de nação entre os membros. Benedict Anderson (2008) afirma que os indivíduos se agrupam em "comunidades imaginadas", uma ligação estabelecida a partir da invenção de 
sentimentos de pertencimento. As diferenças entre os indivíduos são diluídas em nome de maior homogeneidade dentro da comunidade:

[...] independentemente da desigualdade e da exploração efetivas que possam existir dentro dela, a nação sempre é concebida como uma profunda camaradagem horizontal. No fundo, foi essa fraternidade que tornou possível, nestes dois últimos séculos, tantos milhões de pessoas tenham-se não tanto a matar, mas sobretudo morrer por essas criações imaginárias limitadas (ANDERSON, 2008, p. 34).

A partir do conceito de "comunidade imaginada" é possível observar que os sujeitos abdicam de sua própria subjetividade, objetivando preservar e defender a nação. Contudo, é importante observar que a nação é um arranjo social plástico e que sofre modificações no decorrer dos anos. Hobsbawm (1990) diz que o mito da nação não é estático e suas mudanças estão relacionadas a acontecimentos históricos e políticos, daí negar a existência de nações originárias e imutáveis. O homem é ativo e responsável pelas contínuas modificações na comunidade, podendo ser visto como o escultor de uma maleável estrutura cultural.

Tal questão é também abordada por Ernest Renan (2006). O autor acredita que a nação é um princípio espiritual e um resultado de complicações profundas na história. Sujeitos são unidos por um sentimento de solidariedade pelos sacrifícios feitos e por aqueles que ainda estão por ocorrer. $\mathrm{O}$ autor atribui ao homem a responsabilidade pela existência da nação e diz que o conceito não está necessariamente relacionado a territórios ou artefatos materiais. Nesse sentido, compreende-se a nação como uma estrutura mediada por seus membros:

A existência de uma nação é (perdoem-me esta metáfora) um plebiscito de todos os
dias, como a existência do indivíduo é uma afirmação perpétua da vida. Oh! Eu o sei,
esta é menos metafísica que o direito divino, menos brutal que o direito pretendido
histórico. Na ordem das ideias que eu vos submeto, uma nação não tem mais que um
rei o direito de dizer à (sic) uma província: "Você me pertence, eu te tomo". Uma
província, para nós, são os seus habitantes; se alguém neste caso tem o direito de ser
consultado, é o habitante. Uma nação não tem jamais um verdadeiro interesse em se
anexar ou em reter um país a seu contragosto (RENAN, 2006, p. 19).

Apesar de haver posições hierárquicas diferentes, não cabe a um indivíduo na posição de liderança tomar os outros membros da comunidade e ditar modificações. Assim como a própria existência da nação, suas transformações passam por aprovação comunitária todos os dias. Os sujeitos assumem a responsabilidade de manter e alterar signos nacionais. Em um dia, o grupo pode valorizar um ritual e considerá-lo sagrado, mas, em outro momento, pode considerar o mesmo ritual profano e aversivo. 


\section{Identidade}

Considerando o protagonismo do homem na construção da nação, torna-se indispensável discutir a construção de sua identidade. Para Erik Erikson (1972), a identidade está relacionada à concepção de si mesmo. Trata-se de um conjunto de valores, crenças e metas com os quais o sujeito está solidamente comprometido. Tais valores e crenças estão diretamente ligados ao contexto cultural e à comunidade em que o indivíduo está inserido. Stuart Hall (2001) afirma que o sujeito pós-moderno possui várias identidades, uma noção diferente de períodos como o iluminismo, quando se acreditava que o homem teria uma identidade inata e imutável. $\mathrm{O}$ autor também destaca que em meio à diversidade identitária existem conflitos e contradições. $\mathrm{O}$ homem pós-moderno não tem traços identitários fixos, o que implica em uma reinvenção contínua de metas pessoais, valores e crenças.

No arranjo social contemporâneo, mais do que nunca, a identidade passa a ser uma construção. Zygmunt Bauman (2001) crê que o mundo, antes constituído de objetos duráveis, agora é formado por produtos projetados para imediata obsolescência. A nova situação detém o horror de que qualquer esforço para formação de uma identidade coesa resulta inútil, tendo em vista que indivíduos podem adotar ou descartar identidades como trocam de roupa. A inconstância identitária do homem pós-moderno está ligada ao consumismo. O sujeito passa a ter liberdade para adotar identidades que sejam convenientes e atraentes. Contudo, como qualquer produto, tais identidades têm prazo de validade:

\footnotetext{
Em vista da volatilidade e instabilidade intrínsecas de todas ou quase todas as identidades, é a capacidade de 'ir às compras' no supermercado das identidades, o grau de liberdade genuína ou supostamente genuína de selecionar a própria identidade e de mantê-la enquanto desejado, que se torna o verdadeiro caminho para a realização das fantasias da identidade. Com essa capacidade somos livres para fazer e desfazer identidades à vontade. Ou assim parece (BAUMAN, 2001, p. 98).
}

Bauman (2001) objetiva explicitar a existência de uma contínua busca por novas roupagens identitárias. Para continuar consumindo, o indivíduo não pode consolidar sua escolha e, consequentemente, encara a indispensabilidade de flexibilizar seus atributos. O consumismo estimula o anseio pelo novo. Assim, pode-se inferir que a identidade nacional e o conceito de nação também podem passar por transformações. Trata-se da oferta de novas possibilidades de existência àqueles inseridos na arena nacional. É importante destacar que tal fenômeno pode não se manifestar da mesma maneira em todas as comunidades. Assim, torna-se indispensável discutir questões referentes à identidade irlandesa, ou irlandesidade, emoldurada por parâmetros sociais contemporâneos. 


\section{Irlandesidade e o Tigre Celta}

A Irlanda desenvolve sua identidade nacional em meio a eventos conflituosos, essencialmente pautados em resistir ao processo colonial imposto pela coroa inglesa. Segundo Jane Ohlmeyer (2016), o "longo período de usurpação" teve início no século XII, o que tornou a Irlanda a primeira colônia da Inglaterra. Tal condição não aproxima as duas nações culturalmente. As diferenças tornam-se mais evidentes, segundo Ohlmeyer (2016), a partir da reforma protestante de 1530 na Inglaterra. A enorme população católica na Irlanda representava uma verdadeira ameaça ao domínio inglês, o que demandou a criação de medidas para “civilizar" e "anglicizar" a população local:

\footnotetext{
Um elemento central disso foi o amplo uso das leis inglesas, a promoção da língua, da cultura, da arquitetura, da religião (protestantismo) e das práticas agriculturais inglesas estabelecidas. O imperialismo inglês no início da Irlanda moderna foi, portanto, de exploração e movido por interesses militares, políticos, culturais, religiosos e econômicos, e pela determinação de colonizar a ilha com colonos britânicos (OHLMEYER, 2015, p. 72).
}

Assim, a coroa inglesa busca subjugar o povo irlandês obliterando os traços culturais locais e promovendo seus próprios costumes. O objetivo foi estabelecer um processo progressivo de repressão e, consequentemente, submeter o território a um governo inglês. Segundo Brian Glynn (2016), o Ato da União de 1800, mesmo enfrentando resistência, encorpou a Irlanda ao Reino Unido da Grã-Bretanha e Irlanda. O autor reporta que Dublin perdeu o status de capital, passando para a condição de cidade provincial no século XIX. Porém, conflitos em oposição ao controle britânico foram recorrentes e, provavelmente, um dos mais importantes foi a Revolta da Páscoa em 1916.

Odmeyer (2016) afirma que o levante de 1916 teve o intuito de proclamar uma República Irlandesa livre. Locais estratégicos no centro de Dublin foram ocupados por um grupo de insurgentes e, perante espectadores admirados, Patrick Pearse proclamou uma República Irlandesa Livre. Alexandre Sampaio (2008) aponta James Connoly como aquele que conduziu a rebelião. Ele tinha interesse em estabelecer um movimento socialista no país, era líder de um partido trabalhista emergente e fundou o Exército Civil Irlandês.

Sampaio (2008) também diz que o conflito foi impulsionado a partir da ideia de uma Irlanda livre, católica e gaélica. No período, houve uma busca pelo renascimento de heróis, mitos e sagas anteriores à invasão inglesa. Assim, a revolução, apesar de objetivar Revista Graphos, Vol. 20 n. 1, 2018 | UFPB/PPGL | ISSN 1516-1536 
principalmente uma conquista política, estava envolvida em um "nacionalismo cultural". Tratase da convicção segundo a qual a essência e a espiritualidade de um povo são tidas como subsistentes em sua cultura, a ela conectadas pela Antiguidade e pré-história (SAMPAIO, 2008, p.38).

Em meio à Primeira Guerra Mundial (1914-1918), os britânicos tiveram uma resposta tempestiva e sufocaram o levante em seis dias. Os líderes foram submetidos a julgamento perante a corte marcial e executados, o que não significa que o movimento não deixou sua marca na identidade nacional irlandesa:

A rebelião foi mal-sucedida, mas, com as execuções de Connolly e Pearse, os irlandeses ganharam outros heróis. Baseado em seus esforços, a Irlanda chegaria à independência em 1922 (SAMPAIO, 2008, p. 38).

O surgimento de personagens históricos ligados à Revolução de Páscoa foi uma contribuição para fortalecer o senso de nacionalismo na comunidade. A Irlanda passa a ter mais heróis ligados a eventos recentes e sua presença na memória da comunidade fortalece as intenções separatistas. Agora, não necessariamente, a luta precisa buscar referências em passados tão longínquos. Assim, observa-se que o irlandês reforça seu agrupamento em solidariedade a sacrifícios do passado e, tal como afirma Ernest Renan (2006), também por aqueles que ainda estão por ocorrer.

Porém, as ideologias nacionais estão em constante mudança e a irlandesidade não é uma exceção. Passando pela conquista da independência em 1922 e a proclamação da República em 1948, chegamos a meados de 1990, um período de grande desenvolvimento econômico conhecido como Tigre Celta - um fenômeno que modificou a demografia e o imaginário local. Segundo Colin Coulter e Steve Coleman (2003), vários termos foram pensados com o objetivo de nomear o processo de transformação econômica na Irlanda, mas o "Tigre Celta" atravessou a esfera da economia e passou a ser usado no cotidiano da população. Em 1994, Kevin Gardiner, da empresa de investimento americana Morgan Stanley, comparou o desempenho econômico da República da Irlanda com a dos "tigres" econômicos do sudeste asiático - Taiwan, Cingapura, Coréia do Sul e Hong Kong. Assim, ainda segundo Coulter e Coleman (2003), Gardiner cria uma metáfora que passou a ser usada regularmente por um grande número de pessoas na Irlanda, chegando a tornar-se banal.

Coulter e Coleman (2003) afirmam que as novas relações corporativistas implicam também em uma série de mudanças em valores e práticas morais da população. Tal aspecto pode favorecer a invenção de novos itinerários de vida e levar o irlandês a penetrar na dinâmica 
capitalista. Os autores também acreditam que as mudanças do Tigre Celta não implicam na obliteração de práticas convencionalmente consideradas tradicionais. A pós-modernidade permite tanto a coexistência de costumes do passado e presente quanto o renascimento de práticas mais antigas.

Outro aspecto do período é a mudança na população das cidades irlandeses, sobretudo na capital Dublin. A Irlanda do Tigre Celta torna-se uma nação cosmopolita e bastante atraente para aqueles que querem ou precisam deixar seus países de origem. Mas, tal como discutido por Coulter e Coleman (2003), apesar de atrair imigrantes e acolher refugiados, a comunidade irlandesa nem sempre é receptiva. $\mathrm{O}$ autor afirma que enquanto alguns povos são recebidos calorosamente, aqueles oriundos de nações africanas são frequentemente hostilizados. Além disto, a mídia deturpa a imagem de pessoas que vão à Irlanda em busca de asilo e contribui para a perpetuação de práticas racistas.

Há muitas facetas deploráveis no modo como a sociedade irlandesa do sul evoluiu ao longo da última geração. A maneira como refugiados e requerentes de asilo têm sido tratados - especialmente pelas forças do Estado - destacam-se, no entanto, como a mais vergonhosa de todas (COUTER E COLEMAN, 2003, p.28, tradução nossa ${ }^{5}$ ).

Nessa perspectiva, é possível perceber que o Tigre Celta pode levar o irlandês a reinventar sua identidade em um contexto de globalização. As transformações contemporâneas podem desenvolver percepções diferentes e expor as contradições para o anteriormente exaltado passado histórico. Tal fenômeno pode aparecer em representações artísticas e literárias. A poeta Jessica Traynor (2014), em seu livro Liffey Swim, explora uma série de questões ligadas à irlandesidade. No poema "Borderlands", ela cria uma metáfora para o enaltecimento ao passado e suas consequências:

Um fazendeiro perdeu seis ovelhas para corvos, / e um menino, de apenas cinco anos, foi atropelado por um carro, / mas eles cavaram mais e mais fundo, / escavaram uma passagem através da colina / em busca da raiz da pedra (Traynor, 2014, p. 33).

No poema, a pedra é a ancestralidade celta ferozmente buscada para o fortalecimento da identidade nacional, enquanto perdas e acidentes representam o que ficou para trás em nome de tal "comunidade imaginada". É possível observar, então, que autores contemporâneos podem apresentar as contradições dos heróis nacionais e os efeitos negativos do nacionalismo cultural.

\footnotetext{
${ }^{5}$ Salvo quando informado o tradutor, as traduções no decorrer do texto são dos autores do mesmo. Revista Graphos, Vol. 20 n. 1, 2018 | UFPB/PPGL | ISSN 1516-1536
} 
Camila Batista (2015) analisa o romance Star Called Henry, do escritor irlandês Roddy Doyle (1958-), e afirma que a obra é uma crítica ao nacionalismo irlandês, representando líderes da Revolução de 1916 como homens de negócios que defendem a independência para obter vantagens pessoais. Assim, é possível observar uma relação entre os heróis do levante e as contradições morais do Tigre Celta:

\begin{abstract}
A Irlanda vive a ambição pelo novo, pelo moderno e pela ostentação, visando o esquecimento do passado traumático e aumentando a desigualdade e a exclusão. A arte, no entanto, posiciona-se contra o esquecimento e expõe as contradições no presente (BATISTA, 2015, p. 17).
\end{abstract}

Porém, apesar dos males do desenvolvimento econômico, o Tigre Celta pode oportunizar a uma nação, anteriormente homogênea, o diálogo com outras etnias e o desenvolvimento de novas expressões artísticas e culturais. A globalização trouxe para a Irlanda a chance de ampliar a diversidade de suas produções, mas é importante buscar compreender como se dá tal hibridização cultural. A partir da compreensão do irlandês como um sujeito marcado por um intenso nacionalismo cultural, como se dá a relação com o estrangeiro e, sobretudo, o que pode surgir desse encontro?

\title{
Martin Buber, Eu-Tu e Eu-Isso
}

A relação humana é o foco da obra Eu e Tu, do filósofo judeu Martin Buber (1878-1965). Assim, faremos uso de seus conceitos para compreender parte dos processos relacionais presentes no filme Once. Buber (2006) propõe uma compreensão para as formas do ser humano estabelecer relações no mundo. O contato do homem com o outro é mediado através das palavras-princípio Eu-Tu e Eu-Isso. A partir da dualidade de sua própria atitude, o sujeito tem a possibilidade de acessar o mundo de duas maneiras distintas. O que determinará a caráter de sua relação é a palavra-princípio proferida.

Buber (2006) diz que as palavras-princípio são pares de palavras, o que significa que não podem ser compreendidas separadamente. $\mathrm{O}$ Eu do homem é duplo e não pode existir fora da relação com Tu ou Isso:

Quando o homem diz Eu, ele quer dizer um dos dois. O Eu ao qual se refere está presente quando ele diz Eu. Do mesmo modo quando ele profere Tu ou Isso, o Eu de uma ou outra palavra-princípio está presente. Ser Eu, ou proferir a palavra Eu são uma só e mesma coisa. Proferir Eu ou proferir uma das palavras-princípio são uma ou a mesma coisa. Aquele que profere uma palavra-princípio penetra nela e aí permanece (BUBER, 2006, p. 53-54). 
Assim, o autor atribui à relação um lugar primordial na existência humana. Proferir a palavra-princípio é um ato de afirmação do próprio ser. O homem gerencia suas relações e passa a assumir o protagonismo da vida através da linguagem. O interesse de Martin Buber parece ser atribuir à palavra o papel de condutora da existência humana, um elemento que possibilita e configura a experiência existencial.

Buber (2006) oferece conceitos que redefinem as relações humanas. Trata-se de uma filosofia que acredita que o homem não necessariamente enxerga seus pares, sejam eles outros seres humanos ou não, como objetos.

A vida do ser humano não se restringe apenas ao âmbito dos verbos transitivos. Ela não se limita somente às atividades que têm algo por objeto. Eu percebo alguma coisa. Eu experimento alguma coisa, ou represento alguma coisa. A vida do ser humano não consiste unicamente nisto ou em algo semelhante (BUBER, 2006, p. 54).

Através dessa perspectiva, introduz-se a descrição das palavras-princípio. O Eu-Isso está relacionado a experiências de caráter cognoscitivo e utilitário do Eu egótico perante o outro como objeto (VALENTE, 2015, p. 3). Isso implica em um homem que, ao se relacionar com o mundo, estabelece o contato de maneira vertical, assumindo um lugar de detentor de saber sobre o outro. Não existe descoberta: o encontro torna-se um mistério previamente solucionado através das experiências internas do Eu.

Se acrescentarmos experiências internas às externas, nada será alterado, de acordo com uma fugaz distinção que provém do anseio do gênero humano em tornar menos agudo o mistério da morte. Coisas internas, coisas externas, coisas entre coisas! (BUBER, 2006, p. 55).

É, portanto, possível perceber que o ser humano pode sacrificar as surpresas das novas experiências em nome de concepções prévias acerca dos fenômenos da vida. Não se trata dos sentidos que emergem entre o homem e mundo, mas sim de informações pré-concebidas lançadas sobre um outro que é anulado na experiência. Tal atitude confina o outro em um modelo e impossibilita qualquer descoberta ou atualização. $O$ fenômeno repete-se continuamente em uma prisão circular, onde o homem também está preso e inundado por suas próprias informações e ideologias que o afastam da realidade.

Segundo Buber (2006), a palavra-princípio Eu-Tu não tem coisa alguma por objeto. Isso significa que aquele que profere Tu está dentro da relação, aberto à experiência e livre de conceitos prévios que limitam a sua e a expressão do outro. Assim, é possível aceitar o outro em sua totalidade: 


\begin{abstract}
A relação com o Tu é imediata. Entre o Eu e o Tu não se interpõe nenhum jogo de conceitos, nenhuma fantasia; e a própria memória se transforma no momento em que passa dos detalhes à totalidade. Entre Eu e Tu não há fim algum, nenhuma avidez ou antecipação; e a própria aspiração se transforma no momento em que passa do sonho à realidade. Todo meio é obstáculo. Somente na medida em que todos os meios são abolidos acontece o encontro (BUBER, 2006, p. 59).
\end{abstract}

Aquele que diz Tu consegue atravessar fronteiras ideológicas e culturais em direção a um contato autêntico com o outro. É a possibilidade contínua de atualizar suas relações com o mundo, estando disposto a contemplar qualquer que seja a forma da mudança emergente. No contexto contemporâneo, a globalização favorece o acesso a elementos multiculturais e o capitalismo convoca indivíduos ao consumo. Ao tomar posse de tais elementos, o homem contemporâneo aplica camadas identitárias sobre seu eu, o que dificulta seu contato com o outro:

A partir do pensamento buberiano, pode-se afirmar que o homem (pós)moderno não apenas construiu uma couraça que o protege dos chamados do Tu, reforçada pelas culturas, filosofias, religiões, ciências, prazeres, regimes políticos e econômicos, mídias, mecanismos, estatais e aparelhos administrativos (VALENTE, 2015, p. 5).

No trecho, Márcio Valente (2015) relaciona a proposta de Buber com o período social atual, explicitando que o homem contemporâneo pode evitar associar-se ao novo. Os indivíduos parecem fazer uso de seus traços identitários para mediar suas relações. Assim, podemos estar vivendo em uma sociedade que perpetua preconceitos e bloqueia o advento de novidades. Devese destacar que o homem pós-moderno, na verdade, está interessado em consumir novos produtos identitários. Contudo, quando o sujeito vai às compras no supermercado das identidades, ele tende a afeiçoar-se por aquelas mais familiares e afastar-se, ou até mesmo hostilizar, as mais diferentes.

\title{
Once
}

Once é um filme irlandês de John Carney, lançado em 2007 e reconhecido por seu sucesso comercial e por ganhar o Oscar de Melhor Canção Original com "Falling Slowly" em 2008. Segundo Marita Ryan (2010), o filme foi gravado em um curto período de 17 dias e com um orçamento relativamente pequeno (cerca de \$150,000), em parte fornecido pelo Irish Film Board - IFB. A instituição está interessada em financiar produções ambientadas na Irlanda, além de apoiar o desenvolvimento do talento, da criatividade e do empreendimento na indústria cinematográfica local.

Segundo Sara Rodrigues (2011), a IFB favorece projetos designados de "alta qualidade", mas que se destaquem por sua originalidade frente aos já disponíveis no mercado mainstream. Revista Graphos, Vol. 20 n. 1, 2018 | UFPB/PPGL | ISSN 1516-1536 
Isso não significa que o interesse é desenvolver um cinema não-comercial na Irlanda. Na verdade, o objetivo é apoiar projetos que tenham potencial para alcançar sucesso nas bilheterias e gerar lucro. Rodrigues (2011) ainda afirma que a instituição prioriza produções que explorem histórias irlandesas e, principalmente, apresentem seus modos de vida e de pensar o mundo. Tal aspecto parece estar ligado a um interesse em promover a irlandesidade, atribuindo ao filme a função de veicular a cultura local no cenário mundial da sétima arte.

Por receber um financiamento relativamente baixo, Carney não precisou lidar com as exigências da IFB que, geralmente, demanda que os projetos tenham traços irlandeses acentuados. Segundo Ryan (2010), o diretor teve total liberdade e controle artístico, o que contribuiu para uma produção autêntica, no sentido de não fazer uso estratégico ou tendencioso da cultura irlandesa. Não há intensão explicita de comercializar a irlandesidade através do filme. Diretores com maior orçamento tendem a ser pressionados pela expectativa de explorar e enaltecer o país em seus roteiros.

Nesse sentido, é possível observar que, já em seu processo de produção, Once é despido de roupagens identitárias. Provavelmente, o intuito foi favorecer o contato do espectador com uma história que não esteja impregnada de referências à nacionalidade. Trata-se de um filme que convoca a audiência a proferir a palavra sentido $\mathrm{Eu}-\mathrm{Tu}$, o que não significa que qualquer um que assista ao filme tenha uma relação imediata e sem preconceitos com a narrativa. Considerando os aspectos da sociedade contemporânea, nem todos conseguirão atravessar as couraças culturais e responder ao chamado do Tu.

Um outro aspecto relacionado à diluição de traços culturais no filme é o fato de os protagonistas não terem nome. Eles são simplesmente chamados de "garota" e "cara". O nome exerce um papel importante na identidade do sujeito. A partir do nome, é possível identificar a nacionalidade e o gênero de uma pessoa e, em grande parte das vezes, é a primeira informação que as pessoas fornecem ao se conhecerem. Porém, o filme busca descumprir essa previsão social - a ideia preconcebida de que qualquer um teria um nome e essa informação é essencial em uma relação. A camada identitária que nomeia o homem foi retirada, o primeiro conceito foi abolido e o primeiro chamado para relação imediata foi feito.

Mesmo sendo classificado como um musical, é perceptível que os personagens não dialogam ou expressam pensamentos através de canções, o que tende a ser um traço contemporâneo do gênero. As canções surgem nas cenas em ensaios, gravações, ou no próprio processo de composição. Assim, o filme também poderia ser considerado um drama protagonizado por músicos. As canções aparecem como parte da rotina dos personagens e, na 
verdade, são os elementos que dão base à relação do cara e da garota. O fato de não ser facilmente enquadrado em um gênero dá um traço de singularidade à obra. $\mathrm{O}$ espectador pode buscar classificar o filme através de ideias pré-concebidas, mas a intenção parece ser convocálo a perceber a unicidade da obra. Por consequência, aqueles que proferirem Eu-Isso comprometem a própria percepção e podem ter dificuldade em apreender o filme em sua totalidade, considerando que o mesmo está afastado de enquadres e molduras recorrentes do mercado cinematográfico.

O cara é um músico de rua, mas também trabalha na loja do pai consertando aspiradores de pó. A garota é uma imigrante tcheca que vende revistas e flores na rua. O primeiro encontro dos protagonistas acontece em uma rua de Dublin à noite. O cara está cantando e, quando termina, a garota o aplaude e lhe dá dez centavos. Então, ela pergunta se a música tocada é consagrada ou de sua autoria. Ele diz que não é conhecida e que ainda está trabalhando na composição. A garota então questiona por que ele não a toca durante o dia e ele responde: "durante o dia, as pessoas querem ouvir canções que conhecem, canções que possam reconhecer. Caso contrário, não ganharia dinheiro nenhum”. O diálogo pode ser interpretado como uma evidência da impregnação da palavra princípio Eu-Isso no momento social atual. Os indivíduos precisam do embasamento da memória e de experiências anteriores para valorizar o objeto. Afeiçoar-se ao diferente e desconhecido pode ser difícil.

O diálogo também reflete o comportamento dos indivíduos na Irlanda do Tigre Celta. Segundo Batista (2015), críticos do período econômico mostram-se preocupados com as mudanças de uma sociedade que foi construída sob valores comunitários, mas que passa a demonstrar materialismo, individualismo e intolerância. O cara faz comentários irônicos acerca dos dez centavos dados pela garota e deixa claro que a escolha do repertório está baseada em questões financeiras - músicas conhecidas são mais lucrativas. Além disso, ele mostra desinteresse em continuar a conversa, mas acaba cedendo e responde aos questionamentos da garota acerca da pessoa para quem a música foi escrita - uma ex-namorada que está em Londres. Enfim, eles combinam encontrar-se no dia seguinte para que ele possa consertar o aspirador de pó da garota. É observável na passagem que há uma priorização do lucro. A expressão da arte parece estar em uma moldura capitalista, onde seu mérito está relacionado a valores monetários.

A proposta de Once parece estar ligada à tentativa de tratar as vivências dos personagens com realismo. Por vezes, a câmera os grava à distância, o que pode dar a impressão de ser um documentário para quem assiste às cenas isoladamente. Uma considerável parte da trama é gravada nas ruas de Dublin, com pessoas caminhando a todo tempo na frente da câmera e em 
volta dos personagens. Ryan (2010) aponta o momento em que a garota e o cara conversam em uma cafeteria e a câmera os grava do lado de fora através da janela. $\mathrm{O}$ vidro reflete pessoas caminhando que, por vezes, também passam na frente da própria câmera, o que torna difícil visualizar os personagens. Para a autora, a cena reporta o esforço do sujeito em meio à massa do consumismo. Ademais, trata-se do reflexo da diluição da identidade nacional em um contexto de globalização.

Irlandês e estrangeiro desaparecem absorvidos pela massa capitalista e, por consequência, pode ser difícil distinguir ou classificar o homem a partir de sua nacionalidade. Em outros períodos, o nacionalismo e a exaltação de sua própria cultura foram traços inflexíveis na Irlanda. Tais ideologias embasaram lutas e traçaram o caminho para a independência política. Porém, entrelaçados pela globalização, os irlandeses passam a compartilhar o espaço nacional com grupos estrangeiros e a estabelecer um vínculo de intercâmbio cultural. A convivência possibilita a ressignificação de antigos valores, além da possibilidade de adoção de novos costumes.

A fotografia do filme destaca o contraste entre velocidade e isolamento na Irlanda do Tigre Celta. O desenvolvimento econômico transforma a percepção do tempo e o arranjo das relações, o que pode sugerir que os sujeitos tendem a dar preferência à palavra princípio EuIsso. Em meio à velocidade da contemporaneidade, pode ser difícil não evocar experiências anteriores para guiar o contato com o mundo. Recorrer ao passado é uma estratégia que torna a relação superficial, não favorece reflexões críticas, mas que traz conclusões rápidas e elimina a espera. O capitalismo pode dar a uma parcela da população um vasto número de recursos materiais, mas surpresa e novidade podem ser bens de difícil acesso na pós-modernidade.

Após consertar o aspirador de pó com seu pai, o cara leva a garota para seu quarto, que fica no andar cima da loja. Eles escutam música e ele sugere que ela passe a noite lá. Ela não entende bem a proposta, mas ao perceber que se trata de um convite sexual, deixa o quarto bastante aborrecida. O cara a procura no dia seguinte, demonstra seu arrependimento e diz que não acontecerá novamente. Essa sequência de acontecimentos reflete os equívocos guiados pelo Eu-Isso. O homem acredita ser detentor de um saber que pertence a um outro, que, por sua vez, não se dispõe a ceder a uma vontade que não é sua. Segundo Márcio Valente (2015), as palavras princípio não são hierarquicamente opostas e devem ser entendidas como duas intencionalidades diversas. Sem a orientação dos conhecimentos prévios do Eu-Isso, o homem não seria capaz de se desenvolver socialmente, ficando preso em um vazio onde nada é previsto 
ou manipulado. Porém, quando antecipações, conceitos e fantasias medeiam toda e qualquer relação, o homem passa a sofrer com erros e superficialidade.

Eles caminham juntos até a casa da garota, mas, assim que chegam, o cara parece querer se despedir. Há algumas pessoas na entrada e, provavelmente, moram muitos imigrantes no prédio. Ela o convida a entrar e ele responde com outra pergunta: “Eu posso?”. Considerando os aspectos contemporâneos da irlandesidade, tal frase pode não apenas solicitar entrada na casa da garota, mas também expressa insegurança em adentrar um território que não parece ser irlandês. Por muito tempo, a Irlanda teve uma população pouco diversa etnicamente, mas com o advento do Tigre Celta, seus dados demográficos foram consideravelmente alterados. Para Coulter e Coleman (2003), a presença de travellers $^{6}$ e protestantes não deve ser ignorada, mas a população irlandesa sempre foi essencialmente branca e cristã católica. $\mathrm{O}$ autor ainda afirma que o crescimento econômico aumentou a desigualdade social e o racismo no país. Nesse sentido, a atitude do cara pode indicar um desconforto inicial em penetrar um território que não lhe é familiar. Porém, ele aceita o convite, entra na casa, janta, conhece a mãe e a filha da garota e atravessa assim um dos obstáculos do Isso. Ao se despedir, o cara agradece pela companhia e diz: "eu precisava". Sua fala pode expressar a ideia de estar aceitando o chamado do Tu proferido pela garota, rasgando as camadas que o impedem de acessar o mundo em sua totalidade.

É importante destacar o fato de que a paleta de cores usada para representar a cidade e os personagens não transmite os prazeres do consumismo que envolvia a comunidade irlandesa da época - são essencialmente cores desbotadas e tons de marrom e cinza. Once parece tentar transportar o espectador para períodos anteriores ao Tigre Celta ou, talvez, expor o sentimento de sujeitos menos favorecidos e eclipsados pela euforia do desenvolvimento econômico. $\mathrm{Na}$ verdade, a gravação em si não parece ser de 2008, o que convoca a audiência a focar em elementos sonoros, identitários e sociais, para além do imediatismo de efeitos especiais e imagens de cores intensas.

Em uma cena, eles fazem um passeio de moto e chegam a um lugar para ver o mar. Nesse momento, a fotografia dá destaque a paisagens naturais, surgindo assim cores mais acentuadas, como verde e amarelo. O objetivo parece ser apresentar imageticamente um contraste com a cidade, obscurecida pelo consumismo, e seus moradores que negligenciam outros espaços.

\footnotetext{
${ }^{6}$ Segundo Camila Batista (2015), os travellers são um grupo étnico e nômade presente na Irlanda, Reino Unido e Estados Unidos. Eles são recorrentemente alvo de atitudes xenófobas e representados de maneira negativa na mídia.
} 
Outrossim, a Irlanda passa a ser representada de forma mais holística e não apenas como mais uma nação absorvida pela massa do capitalismo.

Durante a caminhada, a garota revela ser casada e informa que seu marido está na República Tcheca. Ela ainda diz que eles são pessoas muito diferentes: ele é muito mais velho e o relacionamento está acabado. Mas, apesar de deixar claro que está bem sozinha, não quer que sua filha Ivonka cresça sem um pai. Nesse aspecto, mesmo proferindo Eu-Tu em várias ocasiões, a garota mostra estar ligada a questões culturais que comprometem sua relação com o mundo e perpetuam sua insatisfação. $\mathrm{O}$ indivíduo pode em vários momentos fazer uso da palavra princípio Eu-Tu, mas muitas vezes pode ser seduzido pela segurança que o Isso oferece. Abrir as possibilidades para o novo e deixar crenças tão enraizadas pela cultura pode ser uma tarefa árdua. É perceptível que ao afastar-se da cidade, a garota fala abertamente de suas angústias. A moldura urbana não favorece a expressão de sentimentos: não há espaço para tais reflexões no contínuo fluxo humano.

O cara decide ir a Londres e reatar com sua ex-namorada, com quem havia rompido após descobrir uma traição. Tendo apenas alguns dias em Dublin, ele convida a garota, que também é pianista e cantora, para cooperar na gravação de algumas canções em estúdio. Em um dos intervalos da gravação, ela toca para ele uma de suas composições. Muito emocionada, ela diz que escreveu a canção para o marido, mas ele odiou quando a escutou. $\mathrm{O}$ cara então propõe que ela vá para Londres também: "vamos escrever muitas canções e viver num bom apartamento". A cena explicita o que germinou da relação dos dois: a música. A partir do uso da palavra princípio $\mathrm{Eu}-\mathrm{Tu}$, foi possível originar arte:

Eis a eterna origem da arte; uma forma defronta-se com o homem e anseia tornar-se uma obra por meio dele. Ela não é um produto de seu espírito, mas uma aparição que lhe apresenta exigindo dele um poder eficaz. Trata-se de um ato essencial do homem: se ele a realiza, proferindo com todo o seu ser a palavra princípio Eu-Tu à forma que lhe aparece, aí então brota a força eficaz e a obra surge (BUBER, 2006, p. 58).

A partir do trecho de Martin Buber (2006), podemos atribuir à garota a posição de aparição. Ela valorizou a música do cara em diversos momentos do filme, auxiliou na negociação com o dono do estúdio e foi fundamental para aquisição do patrocínio. Assim, o cara é convocado a se apropriar de seu potencial criador e pode atravessar obstáculos culturais através da palavra-princípio Eu-Tu. O convite foi aceito e a arte nasceu. Para Ryan (2010), a música em Once atua como uma fonte de comunicação entre a garota e o cara, um rompimento simbólico com a língua inglesa. É a partir da música que a jornada dos dois é desenhada, sendo um elemento relevante para a compreensão da trama. 
Apesar da insistência do cara, a garota ironiza a proposta e pede para que voltem ao trabalho. Ao fim das gravações, ela comunica que entrou em contato com o marido e tentarão fazer o relacionamento dar certo. Após muita insistência, o cara consegue convencê-la a marcar um último encontro, para o qual, no entanto, ela não comparece. Pouco antes de partir para Londres, ele vai à casa da garota, mas ela não está. Para grande parte dos espectadores, sujeitos contemporâneos que aguardam o final feliz, muito recorrente em filmes de romance, Once rompe com tais expectativas e os convoca ao mundo da relação Eu-Tu. Nesse sentido, a audiência tem a oportunidade de ressignificar a importância da previsibilidade das narrativas cinematográficas.

A letra de "Falling Slowly", de certa forma, já antecipava o destino do casal: "Pegue este barco afundando / e aponte para casa / Ainda temos tempo / Eleve sua voz esperançosa você tem uma escolha / Você conseguiu agora” (HANSARD E IRGLOVÁ, 2007). O trecho do refrão pode representar a esperança em um relacionamento que, provavelmente, não seguirá adiante. O cara escreveu a música antes de conhecer a garota, mas o fato de ser a primeira que eles cantam juntos demonstra o quanto ela é significativa na trama. A garota recusa continuamente as propostas do cara, não apenas por ser casada, mas principalmente por acreditar que a relação é inviável.

Porém, até as últimas cenas do filme, o cara mantém a esperança de convencer a garota. Deste modo, é observável que uma parcela considerável da história fílmica atravessa a fé do cara em ter uma relação com uma mulher que, seja dito de passagem, ele mal conhece. Seu interesse parece estar relacionado à possiblidade de uma vivência nova e singular: "Eu não te conheço / mas eu te quero / ainda mais por isso" (HANSARD E IRGLOVÁ, 2007). É observável no trecho da música que o encanto está ligado ao desconhecido, o que vai de encontro com o comportamento dos sujeitos contemporâneos que, geralmente, estão interessados no que lhes é familiar. A atração pela novidade implica em proferir a palavra princípio $\mathrm{Eu}-\mathrm{Tu}$. O irlandês assume uma posição de aceitação frente ao estrangeiro, sendo capaz de deixar para trás o intenso nacionalismo cultural e caminhar para o desenvolvimento de laços e expressões artísticas multiculturais.

O retorno do cara à Inglaterra é mais um fato que reporta a ressignificação do nacionalismo cultural no período do Tigre Celta. Inúmeros conflitos precederam a independência e o desenvolvimento econômico da Irlanda, eventos conflituosos que levaram uma parcela da população local a emigrar em busca de melhores condições de vida. A partir de meados dos anos 90, o aquecimento econômico começa a atrair imigrantes para o país. Assim, 
o irlandês é obrigado a compartilhar sua conquista árdua com outros povos. No filme, assim que o cara deixa Dublin, o marido da garota chega da República Tcheca. A passagem pode estar expondo algo que vai além da convivência. O grande número de imigrantes nas cidades, sobretudo em Dublin, pode levar o irlandês a abdicar de determinados espaços. A presença de estrangeiros pode gerar estranhamento a uma comunidade que, no passado, era essencialmente homogênea - branca e católica. Por conseguinte, o nativo pode evitar adentrar espaços que não sejam mais familiares, cedendo sua arena nacional a outros grupos étnicos.

Por fim, é perceptível em Once o rompimento, mesmo que parcial, com um acordo não explicitado entre alguns produtores de filmes e público: o rapaz e a mocinha ficam sempre juntos no final. Além disso, o filme explora a imigração e o boom econômico, aspectos marcantes da Irlanda do Tigre Celta, através de outros ângulos e possibilita a ressignificação de tais fenômenos dentro da comunidade. Nesse sentido, a proposta de John Carney pode ter o objetivo de auxiliar o espectador a abandonar, mesmo que por cerca de uma hora e meia, seu mundo interno de repetições e vivenciar uma experiência diferenciada com Once.

\section{Considerações finais}

$\mathrm{Na}$ estrada de produções artísticas que enobrecem aspectos culturais locais, John Carney decide pegar a contramão, desconstruindo estereótipos e expondo problemáticas sociais da Irlanda. Primeiramente, é importante destacar seu possível interesse em afastar-se de normas sociais ocidentais. Os nomes de seus protagonistas não aparecem no filme e a narrativa está distante de um ideal romântico. Ao fim, o cara volta para a namorada que o traiu e a garota para o marido que não gosta da sua música. Entretanto, os personagens não parecem estar insatisfeitos ou frustrados com o afastamento. Tal fato reforça a ideia de um encontro mediado pelo Eu-Tu, onde nada é objeto e expectativas não são obstáculos na relação. Assim, a reciprocidade no processo relacional permite a aceitação de diferenças e limites do outro.

Carney também parece explorar o fenômeno imigratório do Tigre Celta contemplando a experiência do estrangeiro. A garota mostra que a ideia de uma Irlanda receptiva, economicamente forte e com oportunidade de emprego pode não ser uma percepção tão assertiva. Nos momentos em que ela vende flores e revistas, ninguém parece estar interessado em comprar. Ela oferece uma revista ao cara no primeiro encontro, mas ele diz não poder comprar. Isso pode mostrar que nem todos os irlandeses foram contemplados com os progressos 
do Tigre Celta e, possivelmente, estrangeiros podem não estar tendo experiências muito lucrativas.

Pode-se concluir que Once promove a ampliação da compreensão dos fenômenos econômicos e sociais do Tigre Celta. As modificações econômicas têm aspectos nocivos que não podem ser negligenciados. A partir do filme, Carney dá voz a grupos esquecidos em meio à euforia do boom econômico irlandês. Além de expor questões econômicas, Once mostra que ideologias ligadas a um nacionalismo cultural irlandês podem estar sendo diluídas a partir de um processo de hibridização demográfica. A garota atrai o cara a experienciar a realidade dos estrangeiros e, assim, ele enxerga tais pessoas para além de traços nacionais. Ela o convoca a dizer Tu e a quebrar as lentes culturais que embasam e limitam a visão dos novos sujeitos que formam o mosaico identitário da Irlanda contemporânea.

Por fim, Once não tende à previsibilidade e permite que o espectador se surpreenda com a narrativa. A partir do conceito de homem contemporâneo, o filme pode propor que para consumir a totalidade dos elementos culturais comercializados pela globalização é preciso proferir Eu-Tu e desvencilhar-se de estereótipos que comprometem a relação. Assim, a palavra princípio $\mathrm{Eu}-\mathrm{Tu}$ torna-se adequada ao momento pós-moderno e suas contínuas transformações. Dentro da perspectiva buberiana, a frase que precede o título no cartaz promocional em português pode expor a premissa de que a relação humana é um processo singular: "Com que frequência você encontra a pessoa certa? Apenas uma vez". Portanto, no filme, a relação humana é vista em sua unicidade. O homem que busca a repetição de experiências anteriores no presente está condenado a um ciclo infinito de equívocos e frustrações.

\section{Referências}

ANDERSON, B. Comunidades imaginadas: reflexões sobre a origem e a difusão do nacionalismo. Tradução de Denise Bottman. São Paulo: Companhia das Letras, 2008.

BATISTA, C. Entrelaçando temporalidades: passado e presente em A star called Henry, de Roddy Doyle. São Paulo, USP, 2015. 130f. Dissertação (Mestrado em Letras) - Programa de Pós-Graduação em Estudos Linguísticos e Literários em Inglês, Faculdade de Filosofia, Letras e Ciências Humanas, Universidade de São Paulo, São Paulo, 2015. Disponível em: $<$ http://www.teses.usp.br/teses/disponiveis/8/8147/tde-06102015151653/publico/2015_CamilaFrancoBatista_VCorr.pdf >. Acesso em: 01 jun. 2018.

BAUMAN, Z. Modernidade Líquida. Tradução de Plínio Dentzien. Rio de Janeiro: Jorge Zahar, 2001.

BUBER, M. Eu e Tu. Tradução de Newton Aquiles Von Zuben. Rio de Janeiro: Rocco, 2006. 
COULTER, C.; COLEMAN, S. The End of Irish History? Critical Reflections on the Celtic Tiger. Manchester: Manchester University Press, 2003.

ERIKSON, E. Identidade, juventude e crise. Tradução de Álvaro Cabral. Rio de Janeiro: Zahar, 1972.

GLYNN, B. Roger Casement: De Diplomata Britânico a Revolucionário Irlandês. Tradução de Alzira L. V. Allegro. Lectures: 2016. Munira H. Mutran e Laura P. Z. Izarra (eds.). São Paulo, Humanitas, 2016.

HALL, S. A identidade cultural na pós-modernidade. Tradução de Tomaz Tadeu da Silva e Guacira Lopes Louro. 5. ed. Rio de Janeiro: DP\&A, 2001.

HOBSBAWM, E. Nações e Nacionalismo desde 1780. Tradução de Maria Célia Paoli. São Paulo: Paz e Terra, 1990.

OHLMEYER, J. 1916: Contextos e Consequências. Tradução de Alzira L. V. Allegro. In: Lectures: 2016. Munira H. Mutran e Laura P. Z. Izarra (eds.). São Paulo, Humanitas, 2016.

ONCE. Direção: John Carney. Produção: John Carney. Dublin: Buena Vista International, 2007. 86 min.

RENAN, E. O que é uma nação? 1882. Revista Aulas: Unicamp, p. 21, 2006. Disponível em: < http://www.unicamp.br/ aulas/VOLUME01/ernest.pdf>. Acesso em: 02 fev. 2018.

RODRIGUES, S. A representação da Irishness no cinema nacional irlandês. Lisboa: ULisboa, 2011. 114 f. Dissertação (Mestrado em Cultura e Sociedade na Europa) Faculdade de Letras, Universidade de Lisboa, Lisboa, 2011. Disponível em: <http://repositorio.ul.pt/bitstream/10451/6800/1/ulfl106448_tm.pdf>. Acesso em: 15 jun. 2018.

RYAN, M. Sounding Different Notes: Approaching the Other through Music in John Carney's film Once. 2010. Disponível em:

<http://www.otherness.dk/fileadmin/www.othernessandthearts.org/Publications/Journal_Othe rness/Otherness_Essays_and_Studies_1.1/Sounding_Different_Notes.pdf $>$. Acesso em: 12 fev. 2018.

SAMPAIO, A. O olhar pós-colonial na construção de uma identidade irlandesa: um estudo da peça Translations, de Brian Friel. São José do Rio Preto: UESP, 2008. 248 f. Dissertação (Mestrado em Letras) - Instituto de Biociências, Letras e Ciências Exatas: Universidade Estadual Paulista, 2008. Disponível em:

<https://repositorio.unesp.br/bitstream/handle/11449/99117/sampaio_a_me_sjrp.pdf?sequenc $\mathrm{e}=1$ \&isAllowed=y>. Acesso em: 21 jun. 2018.

TRAYNOR, J. Liffey Swim. Dublin: Dedalus Press, 2014.

VALENTE, M. A Filosofia do Diálogo e os fragmentos biográficos de Martin Buber. REVISTA HUM@NAE. Recife, v. 8, n. 1, 2015. Disponível em: <http://humanae.esuda.com.br/index.php/humanae/article/view/174/88>. Acesso em: 12 fev. 2018. 